International Journal of Social Sciences and Humanities
Available online at http://sciencescholar.us/journal/index.php/ijssh
Vol. 2 No. 1, April 2018, pages: $1 \sim 9$
e-ISSN: 2550-7001, p-ISSN: $2550-701 \mathrm{X}$
http://dx.doi.org/10.29332/ijssh.v2n1.70

\title{
Representation of Female Characters through Item Songs in Selected Hindi Movies
}

\author{
CrossMark \\ Kajal Kapoor a \\ Article history: Received 10 June 2017, Accepted in revised form 5 January 2018, Approved 20 January 2018,
} Available online 25 January 2018

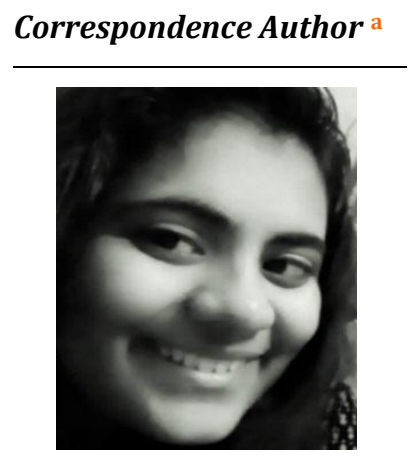

Keywords

Degraded language;

Item songs;

Lyrics;

Objectification;

Women;

\begin{abstract}
The research aims to show how Item songs in Hindi Cinema have degraded its language and how they project women as mere objects. These Item Songs are not directly related to the story but to fetch audience and crores at Box-Office, several filmmakers place item numbers in the movies. Item songs present women in filthy clothes, vulgar lyrics, and their body parts are presented inappropriately. Dance moves and the way of presentation of these songs make it more obscene. Initially, actresses who played vamps on screen or appear for guest appearances in movies used to feature in such songs. But nowadays leading actresses also get featured in such songs as it gives rise to their career. Therefore this research focuses on the point that item songs are meant for entertainment, not for the objectification of women, and hence presentation and projection of women in Hindi movies should be changed more positively.
\end{abstract}

e-ISSN : 2550-7001, p-ISSN : 2550-701X ๑ Copyright 2018. The Author. SS Journals Published by Universidad Técnica de Manabí. This is an open-access article under the CC BY-SA 4.0 license

(https://creativecommons.org/licenses/by-sa/4.0/) All rights reserved.

\section{Contents}

Abstract

1. Introduction

2. Research Method

3. Results and Analysis

4. Conclusion

Acknowledgements

References

Biography of Authors

a Masters in English Language with Communication Studies, Christ University 


\section{Introduction}

Movies are considered as a stress reliever for many people, and to give audience break from their hectic schedule; it acts as a source of entertainment. ${ }^{18}$ Movies are a popular medium of mass utilization which plays a pivotal role in shaping opinions, building images and strengthens authoritative cultural values among the masses. The basic idea of this paper is to focus on the Item Songs of selected Hindi movies and present how things have been mold throughout these years in the industry. Initially, songs and dance sequences were made to give the audience a break from the story, but nowadays these item numbers are made to fulfill the male urge and objectify women. $^{1}$

In today's world, there are several feminist points of views which talk about equality and on the other side Bollywood (which is considered the influential medium of media) depict women dominated by a patriarchal society and use degraded language for them in the form of Item songs. ${ }^{11,12}$ The paper aims to examine forms of oppression against women in songs that are not questioned and bring forth language in the form of Item songs which is degrading women position in society. The basic purpose of taking this study is that in today's world we talk about our rights and equality, but we have forgotten how to protect it. Everyone enjoy Item Songs in the name of entertainment and fun but never realize about its projection on the screen. It's not about blaming men or women, but it's about blamed our thinking which needs to be renovated. ${ }^{3}$

\section{Research Method}

The research has incorporated rational procedure to fulfill study aims, where a researcher has to use facts or information which is already available and analyze to make a critical evaluation of the material. In the present study, the available data on Item Songs and how women are projected in Hindi Cinema is used. Data for this study is collected from the secondary sources of data such as journals and websites.

\section{Results and Analysis}

In the article "Entertainment to Exploitation: A Psycho-Analysis of Sexual Objectification of Women in Films/Cinema." Shumaila Ahmed and Juliana Abdul Wahab examined that sexual objectification is the treatment of a person just as a body, an expression of being treated as a body which is merely for the pleasure of men or consumption of male gaze. It's harsh and painful that films are selling sex and not messages. In films, women are portrayed as an object that is an item for the sexual satisfaction of male desires. Bollywood is a large medium of influencing people, and such projection of women convey the wrong message to audience especially Indian society. ${ }^{4}$

In the article "Use and Abuse of Female Body in Popular Hindi Films: A Semiotic Analysis of Item Songs." How Item Songs have become an important part of Bollywood Movies. ${ }^{6}$ Women are featured as commodity or objects, to satisfy the male urge, and their bodies are projected as if they are meant for male consumption. Having item number in a movie nowadays is a good trick to seek the attention of viewers and above all vulgar and filthy language enhances the popularity of these songs. Role of item song is to generate publicity by dragging attention of the audience. Initially, vamps or dancers used to perform on such tracks but now to achieve high points in their career; leading ladies also perform on such numbers. ${ }^{6}$

Cinesexuality is "A theory of cinema," which is not 'about' cinema, but about the concepts that cinema gave rise to which are related to other concepts responding to other practices of cinema..." ${ }^{2}$ In the research, it is tried to depict how cinesexuality, in the shape of the item numbers, has emerged as a discussion and exercise in Bollywood. Cinesexuality tries to show how women bodies are objectified and sexually used to make these numbers popular and also the sole aim of such songs are commercial acclaims and to seek the attention of the maximum audience. The theory also focuses how Item numbers are not just about objectification; it also tells the harsh reality of this shinning and sparkling world. There are several middles or lower middle-class boys and girls who try their hard luck to enter this world of Cinema. But several of them are just left to be struggling actors for a longer span of time, and for them, Item Songs are much better opportunity than dancing in an ordinary dance bar or as a background dancer in a local show. ${ }^{13,14}$ Therefore Cinesexuality is not just a theory but an emotion to understand about these Item numbers which on the one hand give rise to the careers of Bollywood Divas, and on the other hand for some people, it proves to be means of earning a livelihood for their families. ${ }^{7}$

Hindi Cinema has been under the influence of Male dominance. Female actors are generally sidelined, or their role gets suppressed by male actors. Hindi Cinema popularly known as Bollywood is one of the major industries in Entertainment sector. Movies generally comprises of plot, dialogues, location, costumes, actor, actresses, songs, dance and to add on masala these days. Item Numbers are becoming more prominent in movies than plot, 
and it has several reasons such as Item Songs help movies in fetching more number of audience, it helps film in making crores possible without even a good story. ${ }^{8}$ Item Songs are dance numbers which sexually objectify women, depict them in filthy clothes, cheap dance moves, and vulgar lyrics. Item numbers do not relate or have any connection with movie or plot directly; their sole purpose is entertainment of the audience. Item numbers usually stand for songs and dance that are sexually designed, and the word Item used to denote two things one is any food item and the second which often people describe if a girl is dressed in any fancy or skin-tight dress. We as a society question girl's dressing but never society thinking? We have come a long way regarding technology, but when it comes to mentality we are still way back and keep on reminding people "Log Kya Kahenge" and especially with girls... Item numbers or Item Songs started way back in 1950's with veteran actresses such as Helen, Aruna Irani, Nadira, Padma and much more were performers who appear in such songs. But Helen is still known as the first original item-girl who popularizes the trend of item numbers, and interestingly cabaret performances/ artists (or characters referred as Mona Darling: which was used to refer way back for sensuous actresses) is not that popular as item numbers. Initially, leading actresses were not ready to perform on such numbers, as they feared to get type cased with the image of Cabaret dancers or item girls, though they were ready to perform courtesan in their films, such songs was a big No for them. Among them emerges Helen who can be called a Cine-Artist as she works as an artist, and that's the reason why she was awarded Padma Bhushan in 2009. She used to dance in sensual numbers, but if we look at them, it never looked vulgar or obscene even this trend continues for several another dance numbers. But after the arrival of actresses like Malaika Arora Khan, Isha Kopikar, Lara Dutta and Urmila Matondkar face of item numbers completely changed as now these dance numbers were made for commercial success and male urge and satisfaction. Women were shown in indecent dresses; Camera angles inaccurately highlighted their body parts and above all the way they were projected was not at all acceptable from all kinds of audience. Lyrics the most important part of songs started degrading. Initially, lyrics of such songs were more fun-filling and different from normal ones, but later lyrics were mainly erotic implying double-meaning (which can be considered in both ways funny and at the same time cheap and obscene) and vulgarity. Even the music and tones are mostly sensuous of item songs. These item songs nowadays are not restricted or limited to actresses who appear for guest appearances or play vamps on screen or female actresses who are popularly known as item girls. These days even lead heroines to choose to perform on such songs as they think an item number can act as a hike in their careers, despite their good work, acting and appearances they favor such songs. Actresses like Kareena Kapoor Khan and Katrina Kaif who have immensely contributed in Hindi Cinema with their powerful performances on screen are okay if they are even referred as Tandoori Murgi or Chikni Chameli, such shameful and derogatory terms are used in these songs but to become top actresses they are fine with it. Almost every item number describe women or their body parts in a sexual context, and the clothes and dance moves in the song make them more ostentatious. But apart from all this, there are some actresses who are completely fine with these item songs as they consider them special songs and dancing or penning down lyrics for such songs is not at all incorrect rather it is also a part of the art. Several item girls were inquired about their views on such songs and they have a completely different opinion about such projection as they are getting the surplus amount of money and are roaming and wandering several wonderful locales around the globe, so they are completely okay with these kinds of songs. ${ }^{15,16,17}$

It's not about complaining or blaming a woman, but it's not appropriate to present women as an object that can be touched or viewed in a lecherous manner without her consent. What kind of messages are these songs trying to convey? Its okay to dance with a group but to try to show that women are to fulfill men fantasies and stating it as innocent entertainment is completely inappropriate. Most importantly why progressive women are projected in such degraded manner- as an ITEM GIRL or to be specific as a commodity on an often basis. Whatever we say and term it as 'Chalta Hai' but in reality, it doesn't work like this. Women in India (and across the world) have worked hard in changing the image of a woman neither to regard them as sex-object. Our country has seen several dowry deaths, rape, molestations and we just blame the system, culture, and norms. But do we realize the contribution of Cinema, objectionable songs, and dances contribution? On a broader scale, we state how it can be related to rape or molestation. But we can't deny the fact that somehow it influences the mindset and if A-list actress is fine with such projection than what we can hope for the rest. The most saddening part is that these actresses are so talented, positive and inspirational in their fields; they talk about equality, voice of modern woman, support campaigns about girl child but still they try to gather more limelight through item numbers, and if someone criticizes about such songs. They will directly oppose and state that its sole aim is to entertain the audience. ${ }^{19,20}$ Well, its fine on their parts as in the end money speaks more than the opinions or self-

Kapoor, K. (2018). Representation of Female Characters through Item Songs in Selected Hindi Movies. International Journal Of Social Sciences And Humanities (IJSSH), 2(1), 1-9. doi:10.29332/ijssh.v2n1.70 
respect of person. But it's unfortunate to see women whom we consider as changing the face of such situations get themselves dragged or become part of such item numbers because of higher opportunities and greed.

Item Songs in Movie are dance numbers which do not have any relation to the plot nor with any actor. Their sole purpose is to entertain the audience and in general sexually objectify women with vulgar lyrics, cheap dance moves, and filthy clothes. Initially, new entrants or actress playing a negative role in Hindi Cinema used to perform on such songs, but nowadays it has become a fashion, and a status symbol for even well-established actresses as these item numbers are considered as a hike for their careers. Dancing on songs has never been considered unsuitable because dance is a superior form of art even for some people its worship. But degrading its level to such an extent can be named as obscene where a single girl is surrounded by plenty of men, where she is dancing for male satisfaction or pleasing their eyes. We regard these songs for fun and entertainment, and the saddest part is that at one part we talk about equality, and on the other side we promote such songs and make them popular. If we look at the picture, it's not just about songs or how it is projected but also how it is sung and how the lyrics have been pen downed. Cinesexuality a theory which states it's not about the Cinema but also the concepts which it gave rise to and an item song is one of those concepts. ${ }^{2}$ Erotic, racy, sparkling, liveliness are few of those adjectives which describe item numbers. Initially few films used to have item numbers, but nowadays the numbers are just increasing as it is regarded as one of the shortest stairways for success, and even if the film doesn't work at least item song will fetch audiences and crores at Box- Office.

But do we realize for the sake of entertaining people we have come a long way and now we are insulting female, their identity, their body-parts and above all treating them as objects and even females to an extent have accepted this state. Popular Hindi movies have given us item numbers to look at the pathetic condition of female and their value in society.

\title{
“Kukkuk Kukkuk Kukkuk \\ Choli Ke Piche Kya Hai Choli Ke Piche 2 \\ Chunari Ke Niche Kyaa Hai \\ Chunari Ke Niche?”' (Alka Yagnik, 1993)
}

Above are the lyrics from movie Khalnayak, song Choli Ke Piche Kya Hai sung by Alka Yagnik, choreographed by Saroj Khan starring Madhuri Dixit. All the details mentioned indicate us about one of the most popular films of its time, and all the prominent personalities are included in this venture. When we hear the lyrics first its sound a bit ticklish but when we listen to them properly, we understand the inner or double meaning of such songs. For instance song Choli ke Pichel neeche kya hai sexually refer to the body parts of a girl and therefore create controversy because of its indecent lyrics and vulgar representation of women. Even the initial words Kukkuk are there to arouse sensuousness for the song which is followed by several other indecent lyrics. Another very famous and popular Item Song Munni Badnaam Hui is from the movie Dabangg starring Lalit Pandit has penned Malaika Arora, Salman Khan and Sonu Sood sung by Mamta Sharma and lyrics. 9,10

\author{
"Munni badnaam hui, darling tere liye \\ Munni ke gaal gulabi, nain sharabi, chaal nawabi re \\ Le zandu balm hui, darling tere liye \\ Munni badnaam hui, darling tere liye", 9,10
}

Usually, if we talk in the Indian context, Munni is referred to a small girl in family or society. Munni is associated with the context of adoring or lovingly addressing girl. But here in the song meaning has been completely changed. Ironically in the song, Munni blames her male counterparts for defaming her and at the same time she addresses them as Darling as well. It particularly shows how patriarchal or dominated by men our society is, on the one hand, Munni is sacrificing her honor and accepting humiliation for the sake of male desire and then at the other hand she is addressing these same men as her Darling. Further; Munni physical beauty is described by stating that she has rosy cheeks, beautiful eyes, and royal walk but she became Jandu Balm for the sake of male desire, describing the helplessness of a girl that she is even ready to become an object for fulfilling male desire or satisfaction. Another few lines cross the level of vulgarity and obscenity such as; 


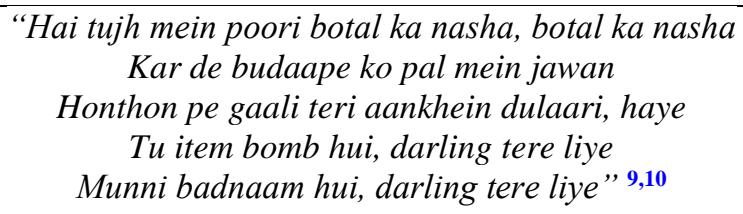

Munni is compared to an energetic and refreshing liquor bottle and regarded as a commodity which can transform an old man into a young person within the fiction of seconds. It shows how forward we have come regarding humiliating women in public with such kind of language. Even once we don't think that comparing a girl with a liquor bottle is way too much and then stating her that she has the same capacity to intoxicating people like a liquor bottle has. After that, there has been a comment on Munni's language how it is filled with indecent abuses but at the same time her eyes are filled with love, and further, she is stated as 'Item Bomb' which denotes she is very hot and attractive and an object for male satisfaction. Is it not an indirect insult to state a girl as an 'Item Bomb,' 'Pattakha,' 'Mirchi Bomb,' 'Phuljari.' Either a girl is a shop of crackers, or she doesn't have any substance in society. It is such a disrespect to refer a girl as a cracker as if she is made to be burned in humiliation by the society. Even some of the females have become so reluctant in getting insulted that they don't even raise their voice or opinion for such insults. This case is similar to one where women are getting beaten by their husbands. While some of them are so troubled with this thought either they commit suicide, or they take a bold step by raising their voice and take actions against it, and there are some who are very fine with the scenario. If someone even tries to help them. They will consider it as an interruption from the outsider, and the most pathetic situation is when the girls are born and brought up in an environment where from their childhood. They are taught that their Husbands are their lords and the entire life they have to listen and follow their commands, they can't even oppose or raise their voice if something happens against their wishes because of husbands opinion matters at the end. Even getting beaten and humiliated from their husband is a sort of satisfaction for them as they consider it as a part of their lifestyle and if people object in it, then they present their view in a sense that they don't even have the right to get beaten or humiliated from society. After such opinion its complicated to blame one section of society as it is the mindsets of society that need to be renovated. Following extract describe helplessness of a girl who is treated merely as a non-living entity that is to satisfy male desire and gratification.

\section{"Amiya se aam hui, darling mere liye" 9,10}

The following line suggests that Munni is no more a little girl; she is all grown up and is ready for any sexual intercourse and the most regretting part is that in the song Munni is happy to announce that she has all grown up and therefore she is ready to serve her body to his male counterparts. Songs with such level of filthiness are a disgrace to society, and it's time to realize the difference between fun and sexual objectification. Another few lines are another example of vulgarity and obscenity such as;

"Aah aa ha

Angdaaiyaan leti hu main jab zor-zor se

Uff angdaaiyaan leti hu main jab zor zor se

Ooh aah ki aaawaz hai aati har oar se

Main to chaloon is qadar

Ke mach jaaye yeh gadar

Hosh wale bhi mad-hosh aayein nazar

Mere photo ko, mere photo ko seene se yaar

Chipka le saiyyan Fevicol se

Fevicol se, Fevicol se, main to kab se

Haye main to kab se hun se ready taiyyar

Pataa le saiyyan miss call se, oh no!",9,10

Kareena Kapoor Khan (who performed on the song) states that she is very famous in this area and everyone is interested in all her activities. She is a beautiful asset and extremely attractive, her small steps create a stir in the society even the people with full senses, lose their sense in front of her glamour and hence she commands to paste her picture on the chest with Fevicol. Further, she states that she is so desperate that she is ready since long

Kapoor, K. (2018). Representation of Female Characters through Item Songs in Selected Hindi Movies. International Journal Of Social Sciences And Humanities (IJSSH), 2(1), 1-9. doi:10.29332/ijssh.v2n1.70 
and can be persuaded by only one miss call. The saddening part about the song is that it is based on women, sung by women, performed by women, apart from men. It is equally enjoyed by women, and this states either we have lost our tastes for songs. Or, its completely normal to objectify women or it is completely fine to have these songs as they are in fashion and maybe people just consider them as dancing numbers, and maybe we don't mind if a woman is assaulted through words.

\author{
"Main to tandoori haye \\ Main to tandoori murgi hu yaar \\ Gatka le saiyyan alcohol se ok! \\ Log kehte hain mujhe main to hu namkin butter \\ Kaat doongi main dil ko meri jawani hai cutter" 9,10
}

Nothing can be worse than this when a female is compared to 'Tandoori Murgi' or 'Namkin Butter,' and she is fine to fulfill the male desire and is happily singing to get consumed for his happiness or to make him satisfied. Such words make us feel to realize where we are going wrong and what has happened to our thinking and what changes can we made to make things normal. It's painful to see women's sexual objectification and comparing her to a commodity. In another song Tu Cheez Badi Hai Mast Mast, a song which once was shown in movie Mohra and once in Machine is considered among one of the favorites in the youth playlist. Similarly, a song like Ooh La La!!! from the movie Dirty Picture was a super hit when it launched but if we notice we get to know it states women as Ladki Tu Hai Badi Bombard. Whether we call Pinky or Sheila either Billo or Chikni, we are just trying to propagate the propaganda of using familiar Indian names and then forming cheap songs and happily objectify women. What has happened to us? We have so many beautiful languages and vocabulary, but we are just degrading our standard using vulgar language, abusing women bodies, projecting them as objects simply for artistic and commercial exploitation. It's not too way back; in 2015 only Rajshri Productions came with a commercial hit of the year Prem Ratan Dhan Payo. The film did great at the box-office, but the audience has mix kind of reviews and opinions about the film. Some liked it, and for some people, it was boring and exaggerating because it has more content for the family audience rather than youth. Another thing is that there are several songs in the movie but not a single item number or spicy dance performance is projected there. Rather it has something very unusual and a very beautiful description of women:

\author{
"Murli ki taano si \\ vedon puraano si \\ Mohan ki geeta ki jaisi tum \\ Tumse hai achai \\ Tumse hi sachai \\ Tulsi ki Sita ki jaisi tum" (Shaan, 2015)
}

A woman is considered as melodious as Murli (Flute), as pure as Veda, Purana and as true as Goddess Sita. It is something rare to find and proves that Cinema is not just about item numbers or entertaining pieces of songs. Still, there are heart touching lyrics, decent language and pure projection on the screen. Therefore, there is no requirement that a girl should be flatter with such beautiful words or humiliate with degraded language because it's not about treating women as Goddess or object (because there are people who don't want girl child in their homes but during the festival of Navratri. They try to bring small girls or Kanya and fed them with food and worship them for that day as they are considered a smaller version of Goddesses). Thus, it's an understanding that everyone has a right to be treated as humans more than anything else.

\title{
4. Conclusion
}

Shoma Chatterji says, "Women in Hindi cinema have been decorative objects with rarely any sense of agency being imparted to them. Each phase of Hindi cinema had its representation of women, but they were confined largely to the traditional, patriarchal framework of the Indian society. The ordinary woman has hardly been visible in Hindi cinema." "Throughout the research, it has been discussed how women have been objectified in Item Songs. The most disgusted and saddening part is that most of the people still don't look into the picture or think about the biases related to the projection of women and have considered and accepted these consequences as a pattern of daily life. People never realize, but there will be a time when there will be no respect for womanhood or regards for one own sister and mother. Hence the main purpose of media should be to increase the 
status of women regarding projection and should convey a positive image so that people not only get inspire but also motivated regarding breaking stereotypes and preconceived notions. But it's not only about blaming women or men for such songs because "Men act, but women also appear. Men look at women; women watch themselves

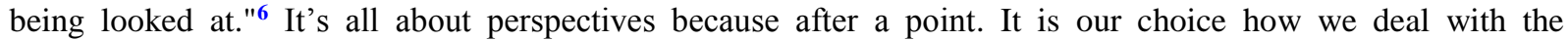
situations, and same applies with Hindi Cinema because many situations have changed where several womencentric movies have come forward and women are shown in ideal roles, and also they carry leading roles in movies like Dangal, Mary Kom, Mardaani, English-Vinglish and much more in upcoming years. Therefore it is not just about the treatment of women; as it is difficult to change the entire projection or procedure, rather it's time to change people mindsets. For entertainment, there is no need of objectification of men or women. It's a proved phenomenon if things are simple or innocent, they can still be beautiful. There is no requirement of having filthy or vulgar content, in item songs just to gather a larger audience and commercial acclaims. Hindi Cinema is a major industry, and there is a huge population who follows or admires watching movies. Every movie is not meant for conveying a social message, but it should not forget that while making content entertaining, objectification of female or treating them as a commodity is completely inappropriate. Every person has a right to get treated as a Human, not as a Tanduri Murgi or Chikni Chameli. Therefore, it's not about excluding or eliminating item songs or numbers from movies. It has become an internal part of films and an essential element of Hindi film industry, but it's projection and presentation and how positively it can be implemented on the screen can be taken into consideration and worked upon in changing the influential face of Hindi Cinema.

\section{Acknowledgements}

The basic idea of this paper is to focus on the Item Songs of selected Hindi movies and present how things have been mold throughout these years in the industry. Initially, songs and dance sequences were made to give the audience a break from the story, but nowadays these item numbers are made to fulfill the male urge and objectify women. Kajal Kapoor would like to express special gratitude towards my mentor Dr. Geetanjali Joshi Mishra and Dr. Arya Aiyappan for their guidance, support, valuable ideas and suggestions throughout in the process of completing my research. 


\section{References}

1. Ahmed, S., \& Wahab, J. A. (2014). Animation and socialization process: Gender role portrayal on cartoon network. Asian Social Science, 10(3), 44.

View in (Google Scholar)

2. Brara, R. (2010). The Item Number: Cinesexuality in Bollywood and Social Life. Economic and Political Weekly, 67-74.

View in (Google Scholar)

3. Kaur, R. (2011). Framing the Body and the Body of Frame: Item songs in popular Hindi cinema. Acta Orientalia Vilnensia, 12(1).

View in (Google Scholar)

4. Patowary, H. (2014). Portrayal of Women in Indian Mass Media: An Investigation. Journal of Education \& Social Policy, 1(1), 84-92.

View in (Google Scholar)

5. Rad, M. T. (2016). Women and Their Portrayal in Indian Cinema. International Journal of Humanities and Cultural Studies (IJHCS) ISSN 2356-5926, 2(4), 1318-1334.

View in (Google Scholar)

6. Sahu, G.K. (2015). "Use and Abuse of Female Body in Popular Hindi Films: A Semiotic Analysis of Item Songs." International Journal of English Language, Literature, and Humanities, vol.3, no.10, Dec 2015, pp.14-25.

View in (Google Scholar)

7. Sharma Gunjan. (2016) "Portrayal of Women in Hindi Cinema.” Anu Books, vol.v, no.2, 2014, pp.1-5. View in (Google)

8. Shaan. (2017) "Prem Ratan Dhan Payo". http://www.lyricsoff.com/songs/Aaj-Unse-Kehna-Hai-Humne- html, 07 Sept. 2017

View in (Google)

9. Sharma Mamta. (2017). "Dabangg”. http://songlyricsinhindi.blogspot.in/2013/05/munni-badnaam-lyrics-inhindi-dabangg.html, 08 Sept. 2017

View in (Google)

10. Sharma Mamta. (2017). “Dabangg2”. http://www.lyricsoff.com/songs/fevicol-se.html, 09 Sept. 2017 View in (Google)

11. Suarta, I. M. (2017). Revitalization of Oral Literature Tradition of Balinese Society Based Character Values As Deradicalism Effort. International Journal of Social Sciences and Humanities (IJSSH), 1(3), 8-16.

View in (Google Scholar)

12. Amerta, I. M. S. (2017). Community Based Tourism Development. International Journal of Social Sciences and Humanities (IJSSH), 1(3), 97-107.

View in (Google Scholar)

13. Syarifaturrahman, W. K., \& Hanafi, N. (2017). The Inflection of Sasak Language in Kuripan Village. International Journal of Social Sciences and Humanities (IJSSH), 1(3), 155-181.

View in (Google Scholar) 
14. Ino, L., \& Dinar, S. S. (2017). Survival Wolio Language in Adulthood in Baubau City: Sociolinguistic Study. International Journal of Linguistics, Literature and Culture (IJLLC), 1(1), 1-11.

View in (Google Scholar)

15. Suwija, I. N. (2017). Identification of Anggah-Ungguh Kruna Balinese Language. International Journal of Linguistics, Literature and Culture (IJLLC), 1(1), 12-18.

View in (Google Scholar)

16. Koutchadé, I. S. (2017). An Exploratory Study of Cohesive features in Selected Excerpts from Sefi Atta's News from Home. International Journal of Linguistics, Literature and Culture (IJLLC), 1(1), 19-28.

View in (Google Scholar)

17. Mathur, S., \& Khanna, K. (2017). Sustainability Practices As A Competitive Edge In Five Star Hotels Of Delhi: A Study on Manager's Perception. International Research Journal of Management, IT and Social Sciences (IRJMIS), 1(1), 1-8.

View in (Google Scholar)

18. Korry, P. D. P., Yulianti, N. M. D. R., \& Yunita, P. I. (2017). Increase the Attractiveness of Local Fruits to the Buying Intention of Hedonic Consumers in Bali. International Research Journal of Management, IT and Social Sciences (IRJMIS), 1(1), 9-15.

View in (Google Scholar)

19. Uberoi, P. (1998). The diaspora comes home: Disciplining desire in DDLJ. Contributions to Indian sociology, 32(2), 305-336.

View in (Google Scholar)

20. Chou, H. Y., \& Singhal, D. (2017). Nostalgia advertising and young Indian consumers: The power of old songs. Asia Pacific Management Review.

View in (Google Scholar)

Biography of Author

\begin{tabular}{|l|l|}
\hline & $\begin{array}{l}\text { Kajal Kapoor is pursuing Masters in the English Language with Communication } \\
\text { Studies from Christ University Bengaluru. She always tries to stay calm and } \\
\text { positive in every circumstance. She believes in the blessings of Almighty and my } \\
\text { parents and in working hard and putting my best foot forward for every situation. } \\
\text { Three of her research articles have been published in renowned journals. As a } \\
\text { student, she is interested in literature, media, mythology and writing research } \\
\text { articles. Email: kapoorrm17111@gmail.com }\end{array}$ \\
\hline
\end{tabular}

Kapoor, K. (2018). Representation of Female Characters through Item Songs in Selected Hindi Movies. International Journal Of Social Sciences And Humanities (IJSSH), 2(1), 1-9. doi:10.29332/ijssh.v2n1.70 